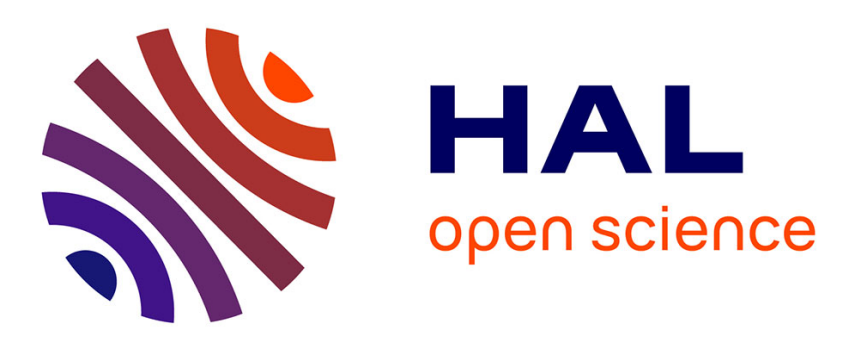

\title{
Observation of type-I and type-II Wannier-stark-effect in InGaAs/InGaAs superlattices
}

R. Schwedler, F. Brüggemann, B. Opitz, A. Kohl, K. Wolter, K. Leo, H. Kurz

\section{To cite this version:}

R. Schwedler, F. Brüggemann, B. Opitz, A. Kohl, K. Wolter, et al.. Observation of type-I and type-II Wannier-stark-effect in InGaAs/InGaAs superlattices. Journal de Physique IV Proceedings, 1993, 03 (C5), pp.C5-445-C5-448. 10.1051/jp4:1993596 . jpa-00251683

\section{HAL Id: jpa-00251683 https://hal.science/jpa-00251683}

Submitted on 1 Jan 1993

HAL is a multi-disciplinary open access archive for the deposit and dissemination of scientific research documents, whether they are published or not. The documents may come from teaching and research institutions in France or abroad, or from public or private research centers.
L'archive ouverte pluridisciplinaire HAL, est destinée au dépôt et à la diffusion de documents scientifiques de niveau recherche, publiés ou non, émanant des établissements d'enseignement et de recherche français ou étrangers, des laboratoires publics ou privés. 


\title{
Observation of type-I and type-II Wannier-stark-effect in InGaAs/InGaAs superlattices
}

\author{
R. SCHWEDLER, F. BRÜGGEMANN, B. OPITZ, A. KOHL, K. WOLTER, K. LEO and H. KURZ \\ Institut für Halbleitertechnik, RWTH Aachen, Sommerfeldstrasse 24, 52074 Aachen, Germany
}

\begin{abstract}
The formation of minibands is demonstrated in photocurrent experiments on shallow $I n_{0.53} G a_{0.47} A s / I n_{0.40} G a_{0.60} A s$ superlattices grown by low pressure metal-organic vapor phase epitaxy. Field-dependent variations of the spectral shape are attributed to Wannier-Stark-localization. Both type-I transitions between electrons and heavy holes and type-II transitions involving light holes confined in the $I n_{0.40} G a_{0.60}$ As layers are observed and identified by comparison with theoretical calculations of the superlattice electronic transitions.
\end{abstract}

The shallow strained superlattice system $I n_{1-x} G a_{x} A s / I n_{1-y} G a_{y} A s$ is an alternative to more conventional quantum well and superlattice systems based on InGaAs/InP, InGaAsP/InP, and In$\mathrm{GaAsP} / \mathrm{InGaAs}$ [1-4] for optoelectronic applications in the $1550 \mathrm{~nm}$ range. It offers a number of interesting and useful advantages: (i) the deterioration of the superlattice interfaces caused by exchange of arsenic and phosphorus during growth of phosphorus containing layers is avoided: $I n_{1-x} G a_{x} A s / I n_{1-y} G a_{y} A s$ is the most simple case of possible structures with constant group V ratios [5] and, (ii) a great variety of different valence band lineups can be achieved by compositional variation of the $I n_{1-x} G a_{x} A s$ layers, including reversal of the positions of light and heavy hole bands.

These important features are possible due to the unusual band structures achievable, as illustrated in Fig. 1 for a superlattice structure: Due to strain induced splitting between heavy- and lighthole bands, the light-hole band edge is above the heavy-hole band edge for $x_{G a}>0.47$. For a certain range of compositions, the strain induced splitting of the light-hole valence band tends to compensate the composition induced change of the $I n_{1-x} G a_{x} A s$ band gap $[1,4,2]$. In an $I n_{1-x} G a_{x} A s / I n_{0.53} G a_{0.47} A s$ heterostructure, this leads to a carrier-type dependent confinement, as illustrated in Fig. 1: The light holes are confined to the Ga-rich layers while electrons and heavy holes are confined to the lattice matched layers.

We have recently reported growth and characterization of high-quality shallow $I n_{1-x} G a_{x} A s /$ $I n_{0.53} G a_{0.47} A s$ multiple quantum wells [6]. In this work, we report on shallow superlattice structures in this material system.

The superlattice is grown by LP-MOVPE on a sulphur-doped InP substrate. It consists of 11 layers of strained $I n_{0.42} G a_{0.58} A s\left(L_{b}=6.9 \mathrm{~nm}\right)$ and 10 layers of nearly lattice matched $I n_{0.51} G a_{0.49} A s$ $\left(L_{z}=7.7 \mathrm{~nm}\right)$ embedded in undoped $I n_{0.70} G a_{0.30} A s_{0.64} P_{0.36}$. The layer parameters are obtained from X-ray diffraction spectra [7]. This structure forms the intrinsic zone of a $\mathrm{p}-\mathrm{i}-\mathrm{n}$-diode. Further details are published elsewhere [8]. 


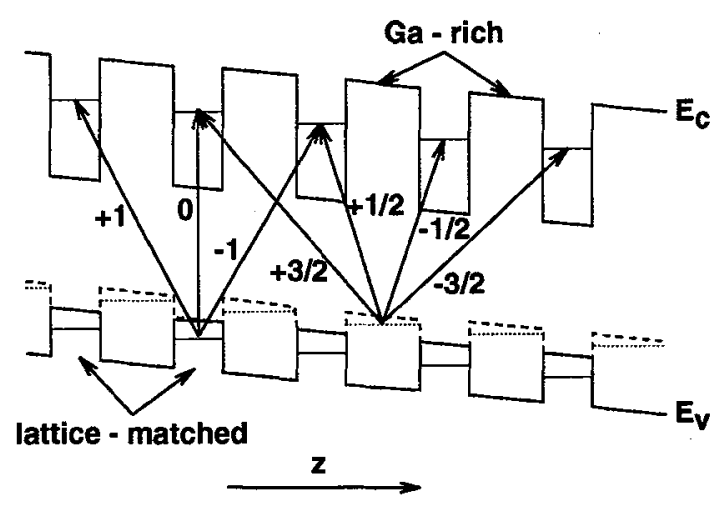

Figure 1: Schematic representation of the band edge profiles for a strained $I n_{1-x} G a_{x} A s /-$ $I n_{0.53} G a_{0.47} A s(x>0.47)$ superlattice. The solid (dashed) lines depict the conduction band edge and the heavy-hole (light-hole) valence band edge, respectively. The arrows indicate several possible type-I electron-heavy-hole $(n=0, \pm 1)$, and electron-light-hole transitions $(n= \pm 1 / 2, \pm 3 / 2)$ resulting from the type-II band alignment.

In Fig. 2 photocurrent (PC) spectra taken at $10 \mathrm{~K}$ are displayed for bias voltages between $0.35 \mathrm{~V}$ and $-3 \mathrm{~V}$. The spectra cover the energetically lowest transitions of the superlattice. The spectrum at the highest forward bias $\left(U_{b}=+0.35 \mathrm{~V}\right)$ exhibits two main features of almost identical intensity near $830 \mathrm{meV}$ and $855 \mathrm{meV}$. The absence of any significant excitonic enhancement in the spectra evidences the miniband regime in this bias range. As the bias changes towards $U_{b}=0 \mathrm{~V}$, the relative intensity of the $855 \mathrm{meV}$ signature increases, and remains dominant for all backward biases. At biases around $U_{b}=0 \mathrm{~V}$, excitonic enhancement of these two main structures indicates the onset of electron wave function localization.

The bias-dependent peak positions are plotted in Fig. 3. Several weak peaks are located by deriving the spectra at bias voltages where the $\mathrm{PC}$ spectra themselves do not allow for precise determination of peak positions. A linear shift of at least four peaks with increasing reverse biases is evident.

The PC maxima are compared with transfer matrix calculations of the superlattice single particle electronic states. Material parameters are interpolated from literature data (see 9). Results of the calculations are shown in Fig. 4, where energies of electron-heavy-hole and electron-light-hole transitions are plotted versus electric field. In Fig. 4, the widths of the markers indicate the magnitude of the corresponding electron-hole overlap integral, giving a measure of the expected oscillator strenths. At zero electric field, two heavy-hole states localized in the lattice-matched confining layers ( $\mathrm{HH} 1, \mathrm{HH} 2$ ) and a single electron miniband (E1) of $25 \mathrm{meV}$ width are obtained. The low confinement energy of the light holes $(14 \mathrm{meV})$ implies almost fully delocalized light holes (LH1) at zero field.

Comparison with the experimental data shown in Fig. 3 confirms these theoretically predicted transitions. The linear slopes in the energy-voltage chart in Fig. 3 for reverse bias $U_{b}<-0.2 \mathrm{~V}$ corresponds to the formation of a Wannier-Stark-ladder originating from oblique transitions between electrons and holes in adjacent confining layers. The slopes of the lines drawn in Fig. 3 are, within $\pm 10 \%$, multiples of $e d \Delta F / \Delta U_{b}=21 \mathrm{meV} / \mathrm{V}$, as indicated in the figure, where $d$ is the superlattice period and $e$ the electronic charge. The change in the electric field is $\Delta F=13.3$ $\mathrm{kV} / \mathrm{cm}$ per $\Delta U_{b}=1 \mathrm{~V}$ bias change, as calculated from the measured thickness of the depletion zone. 


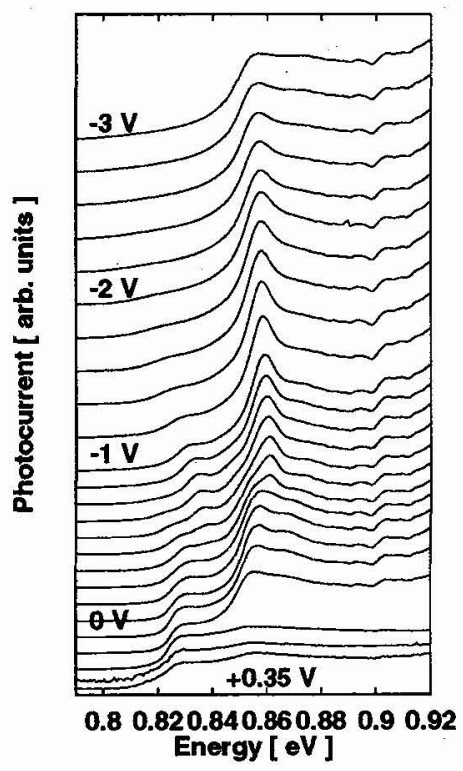

Figure 2: Low temperature photocurrent spectra of the $I n_{0.42} G a_{0.58} A s / I n_{0.51} G a_{0.49^{-}}$ As superlattice taken at various bias voltages.

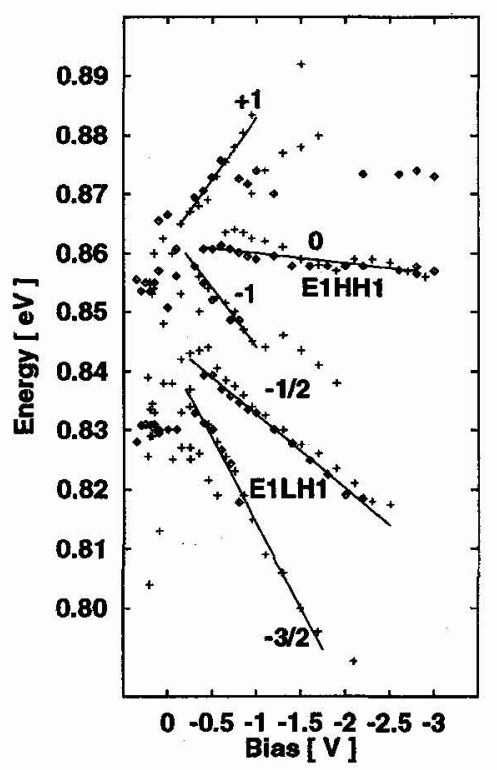

Figure 3: Peak positions from Fig. 2 obtained directly from the spectra $(\diamond)$ and after a derivation procedure $(+)$. Solid lines are guides to the eye.

However, the two lines originating from the electron-light-hole miniband clearly exhibit two different slopes corresponding to fractions of $-1 / 2$ and $-3 / 2$ of the calculated field per superlattice period. In the Wannier-Stark-regime, no light-hole-related spectral structure with zero slope is observed. It can be deduced from Fig. 1 that such a behavior is expected for transitions between electrons confined to the lattice matched layer and light-holes confined in the Ga-rich-layer: The possible spatial separations $d_{n}$ between the localized electron and the light-hole wave function are given by $d_{n}= \pm(2 n-1) / 2 \times d(n=1,2 \ldots)$. For this reason, only odd multiples of $e d \Delta F /\left(2 \Delta U_{b}\right)$ are expected for the slopes of Stark-ladder transitions originating from a type-II-superlattice transition. This type-II behaviour is, of course, also clearly obtained by the calculations summarized in Fig. 4. Due to the very low confinement of the light holes in our structure, no electron-lighthole Stark-ladders with positive slope are expected, as observed in our experiment. The splitting of the electron-light-hole Wannier-Stark states into minibands of $\approx 5 \mathrm{meV}$ is due to the finite size (10 periods) of the superlattice.

In conclusion, we have observed Wannier-Stark-localization in a shallow strained $I n_{0.42} G a_{0.58} A s /-$ $I n_{0.51} G a_{0.49} A s$ superlattice. The unusual valence band alignment corresponds to Wannier-Stark transitions with fractional indices. Theoretical results on the transition energies are in good agreement with experiment.

\section{Acknowledgements}

We are grateful to J. Camassel, H. Mikkelsen, and R. Kersting for useful discussion about the band structure of $I n G a_{0.47} A s_{0.53} / \operatorname{In} G a_{0.40} A s_{0.60}$. This work was supported by the Deutsche Forschungsgemeinschaft under contract no. Ku540/11-2. 


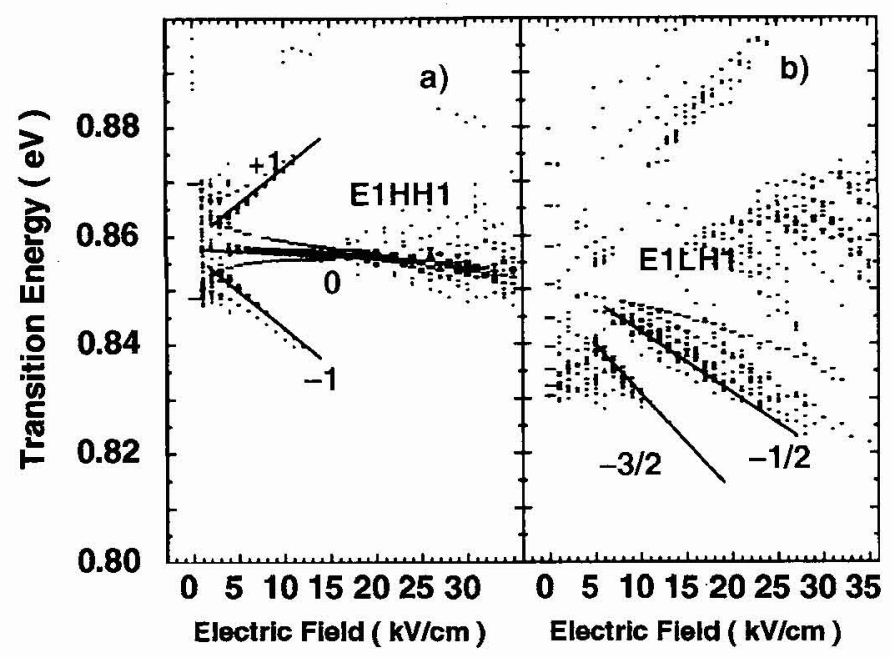

Figure 4: Calculated transition energies $(\mathrm{T}=10 \mathrm{~K}$ ) for electron-heavy-hole (a) and electronlight-hole (b) transitions. The widths of the markers indicate the magnitude of the corresponding electron-hole overlap integral.

\section{References}

[1] G. C. Osbourn. Phys. Rev. B 27, 5126-5128 (1983).

[2] J. E. Zucker, C. H. Joyner, A. G. Dentai. IEEE Photonics Technol. Lett. 4, 432-435 (1992).

[3] M. Quillec, J. Y. Marzin, J. Primot, G. Le Roux, J. L. Benchimol, J. Burgeat. J. Appl. Phys. $59,2447-2450$ (1986).

[4] M. Okamoto, K. Sato, H. Mawatari, F. Kano, K. Magari, Y. Kondo, Y. Itaya. IEEE J. QE 27, 1463-1469 (1991).

[5] A. Mircea, A. Ougazzaden, G. Primot, C. Kazmierski. J. Crys. Growth 124, 737 (1992).

[6] A. Kohl, S. Juillaguet, B. Fraisse, R. Schwedler, F. Royo, H. Peyre, F. Brüggemann, K. Wolter, K. Leo, H. Kurz, J. Camassel. Proc. EMRS Spring Meeting, Straßburg, 1993. to be published.

[7] J. Camassel. Unpublished data.

[8] R. Schwedler, F. Brüggemann, A. Kohl, K. Wolter, K. Leo, H. Kurz. Appl. Phys. A. To be published.

[9] R. Schwedler, B. Gallmann, K. Wolter, D. Grützmacher, M. Stollenwerk, H. Kurz. In NonStoichiometry in Semiconductors, Edited by K. J. Bachmann, H.-L. Hwang, C. Schwab, p. 161-166, Amsterdam, London, New York, Tokyo, 1992. Elsevier. 